Bulletin of Electrical Engineering and Informatics

Vol. 10, No. 3, June 2021, pp. 1129 1141

ISSN: 2302-9285, DOI: 10.11591/eei.v10i3.1909

1129

\title{
The impact of integration of solar farms on the power losses, voltage profile and short circuit level in the distribution system
}

\author{
Abdallah R. Alzyoud ${ }^{1}$, Ali S. Dalabeeh², Ayman Y. Al-Rawashdeh ${ }^{3}$, Anwar Almofleh ${ }^{4}$, \\ Ahmad S. Allabadi ${ }^{5}$, Tamadher Almomani ${ }^{6}$, Ayman Hindi $^{7}$ \\ ${ }_{1,2,3,4,5,6}$ Department of Electrical Engineering, Faculty of Engineering Technology, Al-Balqa Applied University, Jordan \\ ${ }^{7}$ College of Engineering, Najran University, Saudi Arabia
}

\begin{tabular}{|c|c|}
\hline Article Info & ABSTRACT \\
\hline Article history: & This paper introduces a study of utilizing solar energy farm that is integrated \\
\hline Received Oct 21, 2020 & with the national grid based on intensive data availability of solar energy in \\
\hline Revised Dec 20, 2020 & farms into the national grid of Jordan. The study considerd different cases \\
\hline Accepted Mar 27, 2021 & $\begin{array}{l}\text { and, various power system studies for connection points of solar farms to } \\
\text { medium voltage networks. Among these studies are short circuit level, }\end{array}$ \\
\hline Keywords: & $\begin{array}{l}\text { voltage profile and power losses. The main objective of the study is to } \\
\text { analyze impacts of integration of solar farms on distribution systems of the }\end{array}$ \\
\hline Distribution network & chosen areas. Photovoltaic (PV) system with varying penetration levels are \\
\hline Power losses & network. Calculations are performed and models are built using actual data \\
\hline Renewable energy & obtained from the Jordanian power grid with PV interconnection. The effect \\
\hline Short circuit level & of the short circuit level, voltage profile and power losses in the distribution \\
\hline Solar system & system are also analyzed. Finally, the most suitable method of connecting the \\
\hline Voltage profile & solar farm to the national power network is recommended. \\
\hline
\end{tabular}

This is an open access article under the CC BY-SA license.

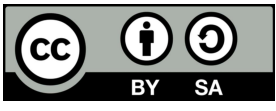

Corresponding Author:

Ayman Y. Al-Rawashdeh

Department of Electrical Engineering

Faculty of Engineering Techonology

Al-Balqa Applied University

Amman, 11134, Jordan

Email: dr.ayman.rawashdeh@bau.edu.jo

\section{INTRODUCTION}

The imported fossil fuels support $88 \%$ of electricity production in Jordan, while $2 \%$ of the demand is fulfilled by the local production of fossil fuels. Therefore, the search for alternative sources of energy has become an imminent issue in Jordan [1]-[5]. Accordingly, Jordan is extensively burdened by the import of fossil fuels, because it consumes approximately $40 \%$ of the country's total budget [6]. The ever-changing political situation of the Middle-East is a constant threat to the energy security of Jordan. These threats disturbed the importing process of oil from Iraq as wel as natural gas from Egypt via Sinai and Syria through the Arab gas pipeline (AGP). This reflects dramatically on the decline in gas import in Jordan is due to the political instability in Syria and Sinai. Therfore, gas import has decreased from 89 to 17 billion cubic feet [7], [8]. Jordan energy sector is encouraging the implemtation of distributed generation in the power system by introducimg solar and wind power plants. This would reduce the reliance on external energy sources by creating feasible alternatives that reduce the total energy usage without any adverse effects on the local community or the energy efficiency [9]. 
The interconnected transmission system in conventional large electric power system is fed by the central generators through step-up transformers and power that is extracted from high voltage networks. These networks go through different transformers to reach the distribution network and fulfill the client's demands. Power losse is minimized by positioning distributed generation (DG) near the demand side, whereas the reactive power compensation improves nearby nodal voltages [10]-[12].

Across the world, mainly in United States and China, there are 20 utility-scale plants of over $100 \mathrm{MW}$ capacities according to international energy agency (IEA). There is an increased participation of vendors to renovate the technology of converting wind potential or solar radiation to useful electrical energy [8]. The vendors are increasingly encouraged by the competitive market to look for continuous development of their products and enhance the quality of electrical power output and conversion efficiency. Different technology providers tend to exhibit different operational performances. The connection suitability of photovoltaic (PV) or wind plant to the electrical grid is ensured by the provider as well as the grid operator. Similar to the transmission system operator (TSO) across the world, TSO in Jordan faces technical issues that can be attributed to renewable energy plants (REPs) ability to connect to the grid. Grid code defines such requirements in a separate connection agreement [8]. The technical performance of REP is simulated and tested to comply with relevant technical requirements in the design or pre-design phase, which further avoids costly design variations after its installation. The modelling of the REP and the electrical grid is characterized by special simulation software that observes the plant's performance before on-site testing that would take place in the commissioning phase [13]-[16].

Several studies have been conducted on the role of PVP under different circumstances. For instance; a study investigated the influence of solar panels on power quality of various transformers and distribution networks. Residential rooftops and solar firms of transformers and distribution networkers were modeled as per the instructions provided by the Canadian Utility data. The overall harmonic currents and distortions occurred on both sides of the transformers were continuously monitored under distinct working conditions. System performance was tested by employing a three-phase transformer and single-phase inverter. Findings of the study indicated that solar power influenced the performance of transformers and distribution networks to a limited extent [17]. Another study focused on the influence of failures of the PVP plants on the PVP energy balance through maintenance data flow and real operations plant specifically in Spain and Italy. Findings indicated a low influence of PVP failures of energy losses. The overall loss of solar field energy was only limited to $4.26 \%$ from all failure energy losses [18]. E. Mulenga [19] examined the influence of integrating solar power in the distribution power grid. The distribution grids were modelled with or without solar PVP in power simulation software. The modelling aimed to examine the steady state influence on the distribution grids. Findings indicated that the integration of solar PVP for the distribution grids significantly increased the voltage level profile. Also, it caused a significant decrease in voltage losses, drop and improvements in the stability of the state voltage of the studied grids. Considering the aforementioned, the current study aims to examine the impact of connecting large-scale PV plants (PVP) on the grid power losses, voltage profile and short circuit current levels of the national grid in Jordan. ETAP software is used to carry out the studies related to short circuit and load flow. Contributions of the study are important as, according to the researcher's knowledge none of the previous study has focused on the influence of connecting large scale PVP plants specifically on the voltage profile, short circuit current levels and grid power losses in Jordanian power system.

\section{NATIONAL GRID OF JORDAN}

It is known that $400 \mathrm{kV}$ and $132 \mathrm{kV}$ national grid interconnects Jordan. A long interconnection is formed by $400 \mathrm{kV}$ lines extended between Aqaba in South and Irbid in North. The routes of the $400 \mathrm{kV}$ lines are shared by $132 \mathrm{kV}$ lines; however, its divergence is increased in order to reach further areas in Jordan. In the central area, the demand of electricity reaches up to $>50 \%$, with congested substations. Approximately, $25 \%$ of the demand is from the North, $20 \%$ from the South, and 5\% from the East. The daily load curves on specific days for winter, spring, and summer of the year 2015 are shown in Figure 1 [20]. The figure clearly shows the minimum load value before sunrise that achieves morning peak at mid of the day, and after sunset shows an evening peak.

Bulletin of Electr Eng \& Inf, Vol. 10, No. 3, June 2021 : 1129-1141 


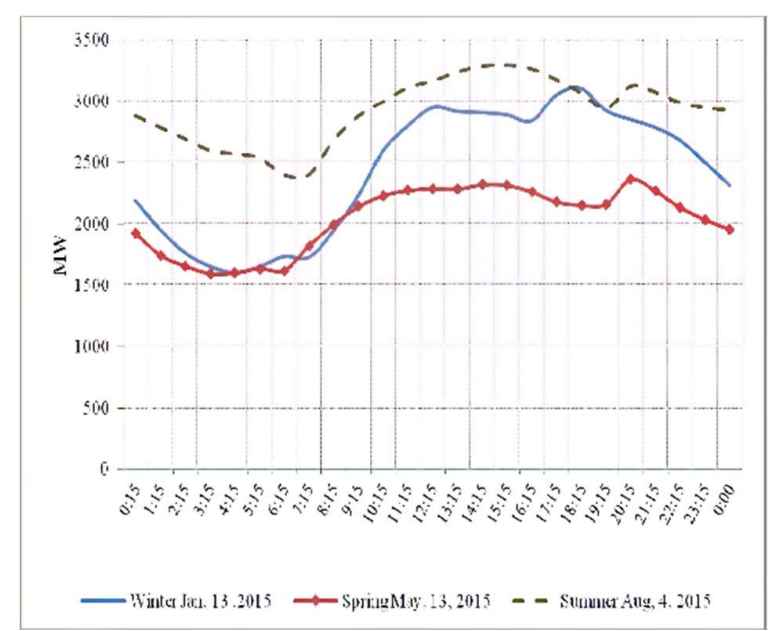

Figure 1. Daily load curves of Jordan power system

\section{RENEWABLE ENERGY POTENTIALS}

Jordan is capable of generating at least $1000 \mathrm{GWh}$ per year, as it is located at the solar belt [21]. The low cost of electricity generated by concentrating solar power (CSP) can be as low as $\$ 0.14 / \mathrm{kWh}$, with storage period of $<6$ hours [22]. The cost $\$ 0.13 / \mathrm{kWh}$ for conventional natural gas burning combustion turbine is compared to offshore wind turbines with cost of $\$ 0.20 / \mathrm{kWh}$ and advanced nuclear with cost of $\$ 0.1 / \mathrm{kWh}$ [23]. The reliance of Jordan on renewable energy is feasible by pairing the low cost of solar power generation with the solar potential of Jordan [24]. Notably, a relatively high solar radiation is available in Jordan that exceeds $2000 \mathrm{kWh} / \mathrm{m}^{2} / \mathrm{yr}$ in the eastern area and $2200 \mathrm{kWh} / \mathrm{m}^{2} / \mathrm{yr}$ in the southern area [25]. Electric power with competitive levelized cost of energy is likely to be produced by Utility-scale PVPs under specific climatic conditions, considering system costs and costs of capital. Remarkable interest has been achieved by the wind speed potential in Jordan that reaches an average value of $5-7 \mathrm{~m} / \mathrm{s}$ (at $100 \mathrm{~m}$ height) in majority of the areas. These areas include the southern and eastern areas of Jordan. The eastern and southern areas are mostly fit in terms of solar radiation, land availability, and wind speed. The Solar radiation map of Jordan is shown in Figure 2 [26].

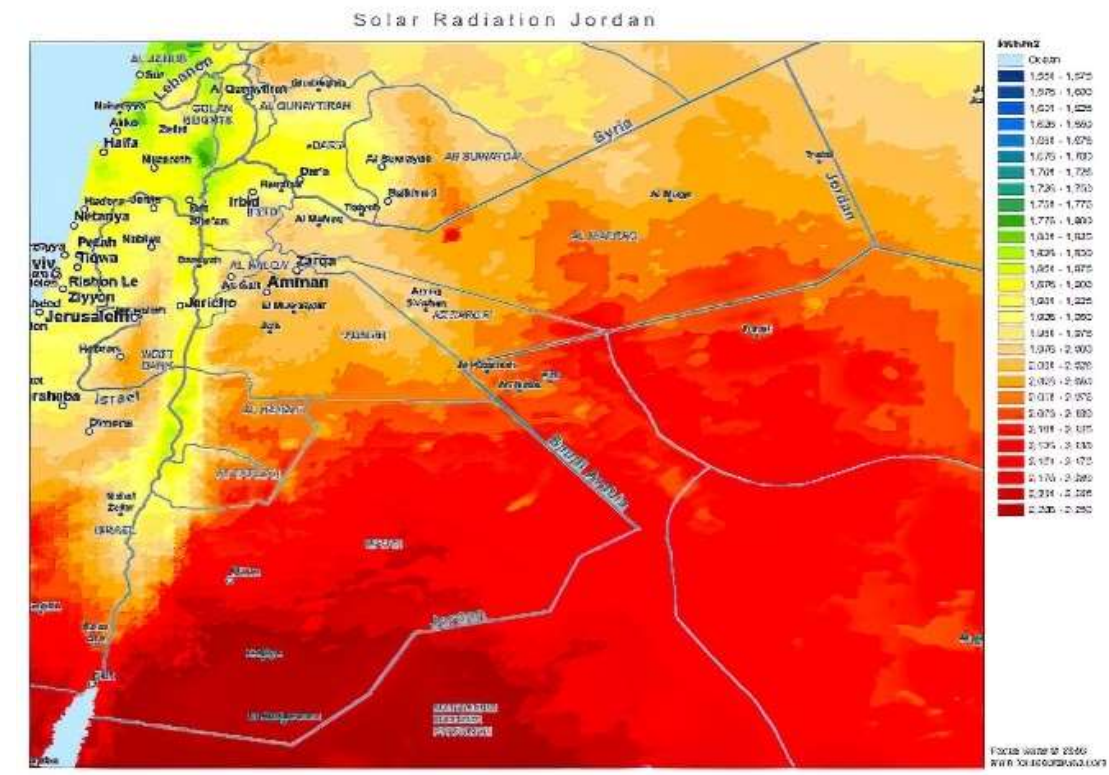

Figure 2. Solar radiation map of Jordan 
In this study, two scenarios with identical PV systems but with different connection points to the distribution network have been discussed. The first connection scenario was to $33 \mathrm{kV}$ Ma'an substation bus, whereas the second to $11 \mathrm{kV}$ bus. The different scenarios have been simulated using energy technology assistance program (ETAP), and then the effects of integration the solar farms into the grid have been analyzed and evaluated.

\section{RESEARCH METHOD}

Potential effects of the grid-connected photovoltaic systems on the distribution systems sources of renewable energy, particularly the PV systems, have become highly important sources. Nevertheless, connecting large PV systems to utility grids can result in many operational problems for the distribution networks. Severity of these problems significantly depends on geography of the installation site and the percentage of PV penetration. Thus, knowledge of the potential effects of large grid-connected PV systems on the distribution networks helps in making informaed and practical decisions before installation and operation of the integrated systems [27].

\subsection{Effects of photovoltaic plants on the voltage profile}

Power is fed with highest voltage level and it is consumed at the lowest voltage level in traditionally designed electricity distribution systems. Due to this, the line voltage generally decreases in proportion to the distance from the voltage source at which the loads are encountered and the measurement is taken. However, there is a need to maintain voltage in the specific range stipulated by guidelines and standards for safety of machinery and appliances. The power utility companies implement numerous technology countermeasures for controlling the voltage within the set range.

On the other hand, the extra power is likely to flow back to the grid, when the power generated by a PV system is more as compared to the electricity consumed at the use point. In such cases, voltage increases and the electric current flow inverts its direction heading towards the end. This issue is not important in urban grids that possess strong networks with limited PV capacities but high grid impedance. However, the voltage can surpass the upper limit if there is an increase in PV penetration or the number of PV systems are integrated with rural grid of lower impedance. If efforts are made to optimize the positioning, when connecting PV with a distribution network, then the voltage profile might be enhanced. This is especially important for feeders of substantial length where drops in voltage are critical [28], [29]. A system with short transmission line $(\mathrm{Z}=\mathrm{R}+\mathrm{j} \mathrm{X})$, receiving end voltage $(\mathrm{V} 2)$, sending end voltage (V1), and connection of a load $(\mathrm{P}, \mathrm{Q})$ is considered at the receiving end, known as a two-port system, to explain the concept of voltage profile. The concepts of system behavior in terms of voltage profile and voltage stability is derived using the two-port system. The representation of two-port system is shown in Figure 3.

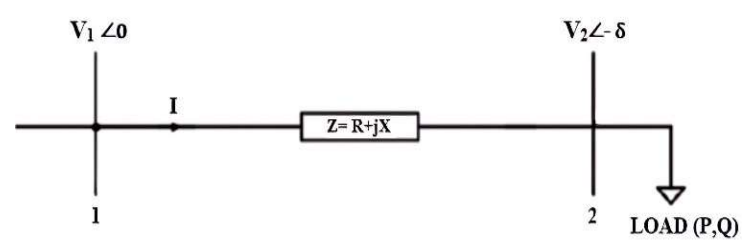

Figure 3. Two-port system

In (1) is derived from analysis of Figure 3 for the voltage relationship between bus 1 and bus 2;

$$
\mathrm{V} 1=\mathrm{V} 2+\mathrm{IZ}
$$

The magnitude of the voltage at the receiving bus can be determined as;

$$
|\mathrm{V} 2|=|\mathrm{V} 1|-((\mathrm{RP}+\mathrm{XQ}) /|\mathrm{V} 1|
$$

In (2) shows the expression of voltage magnitude level and profile (|V2|) for a particular loading and operating condition at bus 2 . The voltage drop is expressed through the third term. The line parameters $(\mathrm{R}$ and $\mathrm{X})$ produces voltage drop $(\Delta \mathrm{V})$. Whereas, load active and reactive power are consumed at the receiving bus 2 . In (3) is expressed as shown in [30];

Bulletin of Electr Eng \& Inf, Vol. 10, No. 3, June 2021 : 1129-1141 
Voltage drop:

$$
\Delta \mathrm{V}=(\mathrm{RP}+\mathrm{XQ}) / \mathrm{V} 1 \mid
$$

Figure 3 showing the two-port grid is integrated with a solar PV power at the load bus as shown in Figure 4. The modification of two-port grid allows the inclusion of a solar PV plant at bus 2 by inserting active power into the bus with a power factor of 1 .

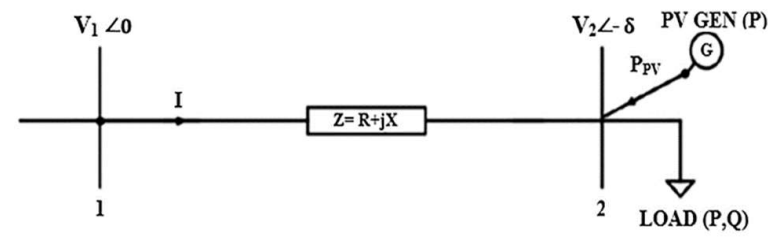

Figure 4. Two-port grid integrated with PV GEN at load bus

Figure 4 shows the modification of two port equations for voltage profile and voltage drop for including solar PV power resulting in (4) and (5).

$$
\begin{aligned}
& |\mathrm{V} 2|=|\mathrm{V} 1|-\left(\left(\mathrm{R}\left(\mathrm{P}-\mathrm{P} \_\mathrm{PV}\right)+\mathrm{XQ}\right) /|\mathrm{V} 1|\right) \\
& \Delta \mathrm{V}=\left(\mathrm{R}\left(\mathrm{P}-\mathrm{P} \_\mathrm{PV}\right)+\mathrm{XQ}\right) /|\mathrm{V} 1|
\end{aligned}
$$

It is noted that implemintation of the solar PV power at bus 2 causes an increase in the voltage level at this bus and reduces the voltage drop along the line.

\subsection{Effects of photovoltaic plants on power losses}

In various cases, large amount of energy is lost when power is transmitted and distributed to the loads, and when the large power plants are built miles away from the point-of-demand. There is a proportionality loss and distance of power travelling in line, which depends on the regional conditions. Power at the points-of-use and depending on availability of solar radiation is produced by the PV systems which offers minimal loss of power. Land is not needed because PV unit can be integrated with, or mounted on, the building demanding electricity. This results in the enhancement of value of the PV system to the grid. The value of on-site generation of the PV output at the point-of-demand is used by majority of the members of IEA. There is significant reduction in the transmission and distribution losses if power is produced at the point-of-use. In (6) and (7) show the active and reactive losses of the line based on the representation in Figure 1 [30].

$$
\begin{aligned}
& \mathrm{P}_{-} L O S S=|\mathrm{I}|^{\wedge} 2 \mathrm{R}=\left(\left(\mathrm{P}^{\wedge} 2+\mathrm{Q}^{\wedge} 2\right) /|\mathrm{V} 2|^{\wedge} 2\right) \mathrm{R} \\
& \mathrm{Q} \_ \text {LOSS }=|\mathrm{I}|^{\wedge} 2 \mathrm{X}=\left(\left(\mathrm{P}^{\wedge} 2+\mathrm{Q}^{\wedge} 2\right) /|\mathrm{V} 2|^{\wedge} 2\right) \mathrm{X}
\end{aligned}
$$

Figure 4 shows the modification of two port equations for power losses for including solar PV power integration resulting as shown in (8) and (9).

$$
\begin{aligned}
& \mathrm{P} \_ \text {LOSS }=|\mathrm{I}|^{\wedge} 2 \mathrm{R}=\left(\left(\left(\mathrm{P}-\mathrm{P} \_\mathrm{PV}\right)^{\wedge} 2+\mathrm{Q}^{\wedge} 2\right) /|\mathrm{V} 2|^{\wedge} 2\right) \mathrm{R} \\
& \mathrm{Q} \_L O S S=|\mathrm{I}|^{\wedge} 2 \mathrm{X}=\left(\left(\left(\mathrm{P}-\mathrm{P} \_\mathrm{PV}\right)^{\wedge} 2+\mathrm{Q}^{\wedge} 2\right) /|\mathrm{V} 2|^{\wedge} 2\right) \mathrm{X}
\end{aligned}
$$

Introducing PV units in the distributed posts brings forth decreased flow of current in the lines. The losses are decreased by the load compensation performed by the integrated PV. As the power losses in the electrical netowks elements are proportional to the square of the current. This effect is particularly clear during the peak loads. There is a marked reduction in active power losses and active component of the line current due to reduction in the active power, which causes total losses. 


\subsection{Impact of the photovoltaic plant on the short-circuit level}

In general, PV grid-connected systems do not significantly contribute to the short-circuit faults which occur at the distribution network side [27], due to the fact that the short-circuit current of a PV array is self-limited, ideally 10.0-20.0\% higher than the maximum rated power current. However, the impact of fault should be reassessed, when the controls are functioning in weak networks, or the controls of the inverters are changed to achieve other functions like voltage support. In any case, suitable coordination of different protection methods (customers' sites, PV-DG, and network) is an important issue to ensure short-circuit protection at varied fault levels.

\section{SYSTEM CONFIGURATION MODEL}

The system configuration model was built using ETAP software and it's shown in Figure 5. The system is composed of electrical grids and PV solar plant. The output of the PV panels is a DC, which is then converted into AC using an inverter connected to the AC bus to which the electrical load is connected.

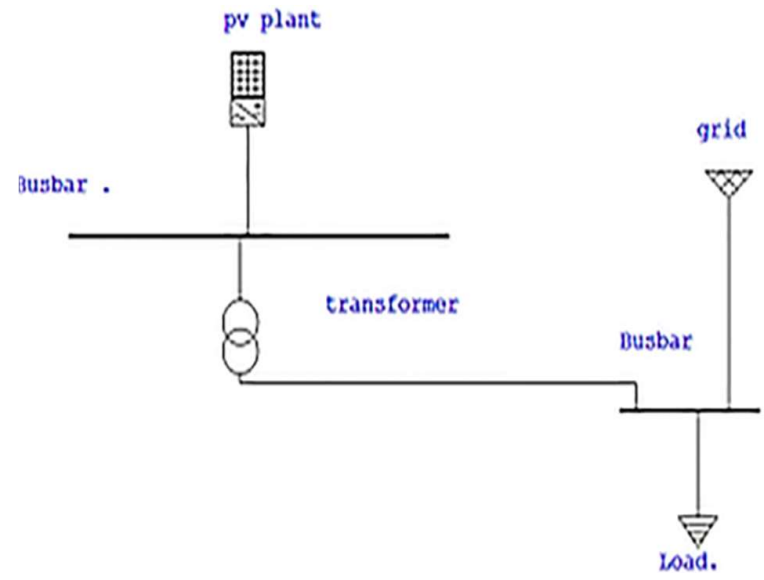

Figure 5. System model configuration

\subsection{Solar data for the selected site}

The obtained from Ma'an region data is shown in Table 1 and is illustrated in Figure 6. The average solar radiation is about $6.2 \mathrm{kWh} / \mathrm{m}^{2}$ per day that is quite high and suitable for electrical power generation.

Table 1 . The monthly average of global horizontal irradiation and air temperature for the considered site in

\begin{tabular}{ccccc}
\multicolumn{5}{c}{ Ma'an region } \\
\hline Month & Ghm & Ghd & Dhd & T24 \\
\hline Jan & 115 & 3.70 & 1.10 & 6.5 \\
Feb & 134 & 4.77 & 1.36 & 7.9 \\
Mar & 193 & 6.21 & 1.60 & 11.4 \\
Apr & 213 & 7.10 & 2.10 & 16.6 \\
May & 249 & 8.04 & 2.08 & 20.6 \\
Jun & 263 & 8.77 & 1.73 & 23.3 \\
Jul & 264 & 8.52 & 1.65 & 24.7 \\
Aug & 242 & 7.82 & 1.76 & 24.7 \\
Sep & 204 & 6.80 & 1.57 & 22.5 \\
Oct & 164 & 5.28 & 1.56 & 18.9 \\
Nov & 122 & 4.07 & 1.18 & 13.1 \\
Dec & 102 & 3.28 & 0.95 & 8.4 \\
Year & 2265 & 6.20 & 1.55 & 16.6 \\
\hline
\end{tabular}

Ghm: Monthly sum of global irradiation $\left[\mathrm{kWh} / \mathrm{m}^{2}\right]$; Ghd: Daily sum of global irradiation $\left[\mathrm{kWh} / \mathrm{m}^{2}\right]$; Dhd: Daily sum of diffuse irradiation $\left[\mathrm{kWh} / \mathrm{m}^{2}\right] ;$ T24: Daily (diurnal) air temperature $\left[{ }^{\circ} \mathrm{C}\right]$.

\subsection{PV system description}

The solar module was chosen for modeling since it is well suited for the applications of photovoltaic systems in Jordan [31]. The key specifications are shown in Table 2. This PV solar system consists of 18 PV

Bulletin of Electr Eng \& Inf, Vol. 10, No. 3, June 2021 : 1129 - 1141 
arrays. Each array contains 6969 solar panels, with an output of 239.7 watt for each panel connecting 23 solar panels in series, called string, to get $704.95 \mathrm{~V}$ and 303 in parallel to get $1670 \mathrm{~kW}$ DC and $2369.46 \mathrm{~A}$ current. These data are used in the SMA central inverter with 2000 KVA and unity power factor output. Table 3 shows the technical data for the inverter. The inverters are connected to $33 \mathrm{kV}$ bus bar which is suitable to their output voltage. The PV-power plant with output $30 \mathrm{MVA}$ at unity power factor is connected to the national power grid to $33 \mathrm{kV}$ Ma'an substation.

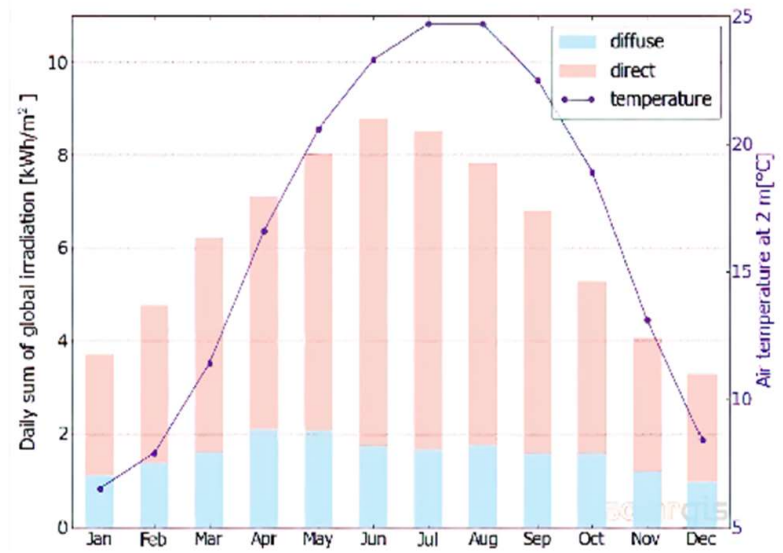

Figure 6. The monthly averages of global horizontal irradiation and air temperature for the site in Ma'an

Table 2. SunivaPanel characteristics (Suniva ART245-60-3-1PV panel data sheet)

\begin{tabular}{ccc}
\hline UNIT & VALUES & THE SUN IVAART 245-60-3-1PV DATA \\
\hline Nominal power [Pnom] & 239.7 & $\mathrm{~W}$ \\
Voltage at Nominal Power [Vmpp] & 30.65 & $\mathrm{~V}$ \\
Current at Nominal Power [Impp] & 7.82 & $\mathrm{~A}$ \\
Open-circuit Voltage [Voc] & 37.08 & $\mathrm{~V}$ \\
Short-circuit Current [Isc] & 8.33 & $\mathrm{~A}$ \\
Voltage Temperature Coefficient & -0.332 & $\% / \mathrm{C}$ \\
Current Temperature Coefficient & 0.036 & $\% / \mathrm{C}$ \\
Module Efficiency & 14.9 & $\%$ \\
Length & 165.3 & $\mathrm{~cm}$ \\
Width & 98.2 & $\mathrm{~cm}$ \\
Area & 1.62 & $\mathrm{~cm}^{2}$ \\
\hline
\end{tabular}

Table 3. Technical data for MV power station $2000 \mathrm{sc}$

\begin{tabular}{ccc}
\hline UNIT & VALUES & THE SMA CENTRAL INVERTER DATA \\
\hline $\mathrm{kW}$ & 2244 & Max. DC power \\
$\mathrm{V}$ & 1000 & Max. input voltage \\
$\mathrm{V}$ & 688 & Rated input voltage \\
$\mathrm{A}$ & 3270 & Max. input current \\
$\mathrm{KVA}$ & 2000 & Output rated power \\
$\mathrm{kV}$ & 6.6 to 35 & Nominal AC voltage \\
$\mathrm{Hz}$ & 50 & Ac power frequency \\
$\mathrm{A}$ & 6 & Max. output current at $20 \mathrm{KV}$ \\
$\%$ & 97.6 & Max. efficiency \\
\hline
\end{tabular}

\subsection{Distribution system description}

The distribution network of Ma'an is fed from the power grid of $132 \mathrm{kV}$ through three $16 \mathrm{MVA}$ step down transformers $(132 / 33 \mathrm{kV})$ to supply the town's load.

\section{SIMULATION USING ETAP}

Energy technology assistance program (ETAP) has been used to simulate the PV solar system integrated with the grid [32]. ETAP is the most comprehensive analysis platform for the design, simulation, operation, and automation of generation, distribution, and industrial power systems. In this paper three cases are studied and analyzed. 


\subsection{Case I: electrical distribution system without PV solar system}

Case I, presents Ma'an electric distribution system which is supplied from the transmission lines operated by NEPCO [33]. The single line diagram of electric distribution system is shown in Figure 7 and the load flow of the distribution system is shown in Figure 8.

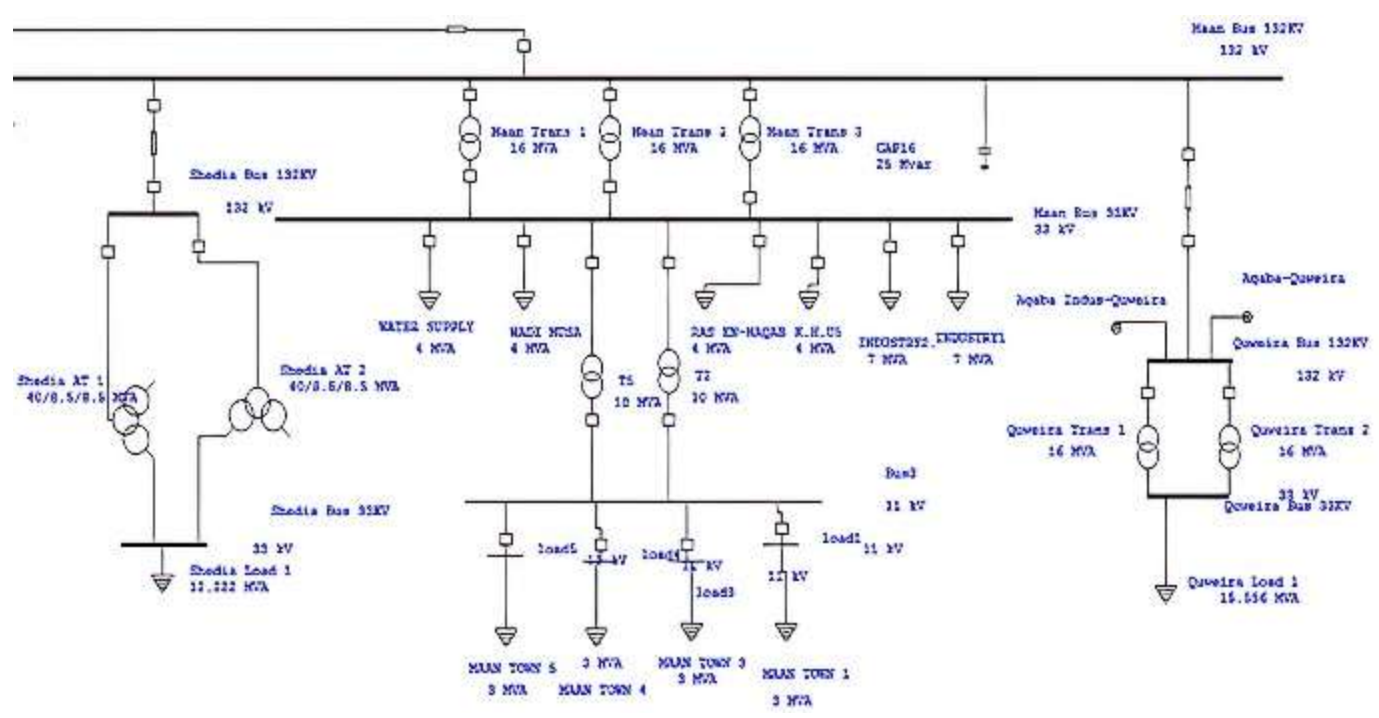

Figure 7. Single line diagram of Ma'an distribution network

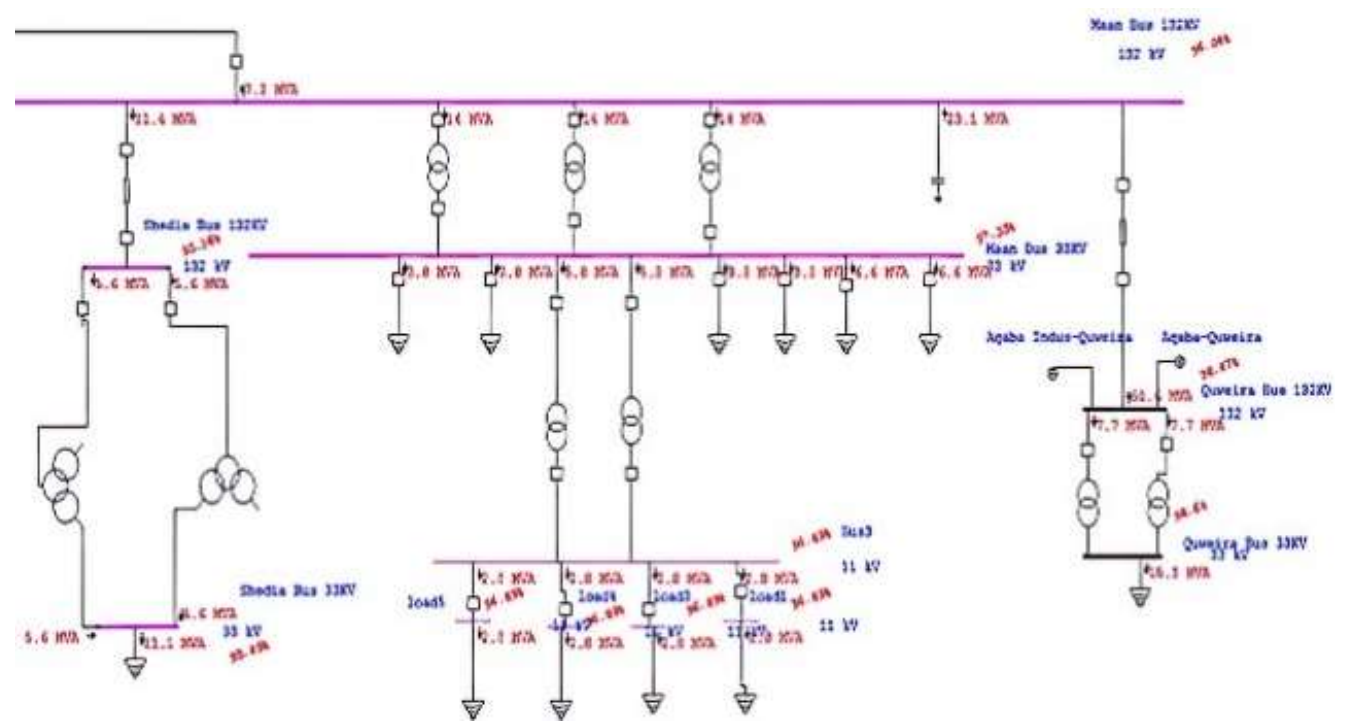

Figure 8. Load flow of the distribution network of Ma'an

\subsection{Case II: PV solar system is connected to $33 \mathrm{kv}$ bus bar at average load}

Case II, presents the distribution system with the solar PV connected to $33 \mathrm{kV}$ bus. The single line diagram of this case is shown in Figure 9. While, the load flow for the transformers and distribution lines is shown in Figure 10.

\subsection{Case III: PV solar system is connected to $11 \mathrm{kv}$ bus bar at average load}

Case III, presents the distribution system with solar PV connected to $11 \mathrm{kV}$ bus. The single line diagram of this case is shown in Figure 11. And the load flow for the transformers and distribution lines is shown in Figure 12.

Bulletin of Electr Eng \& Inf, Vol. 10, No. 3, June 2021 : 1129-1141 


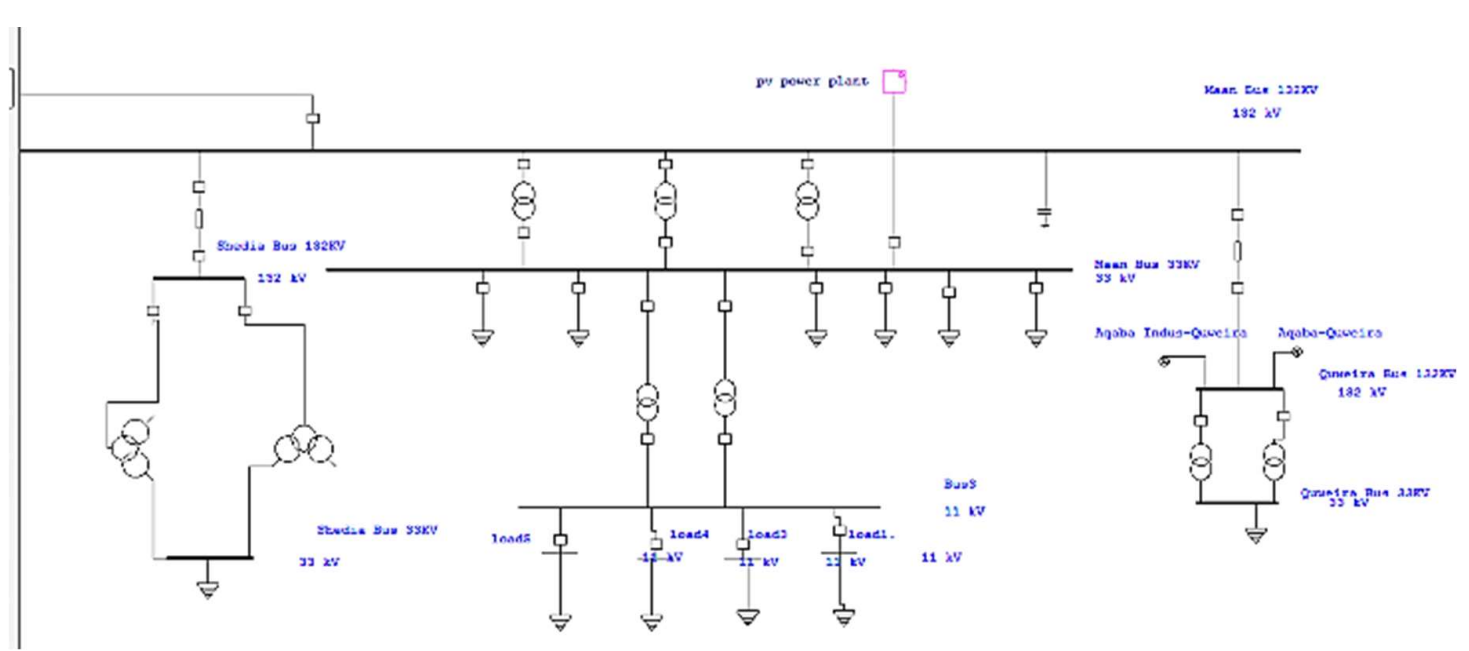

Figure 9. ETAP single line diagram for case II

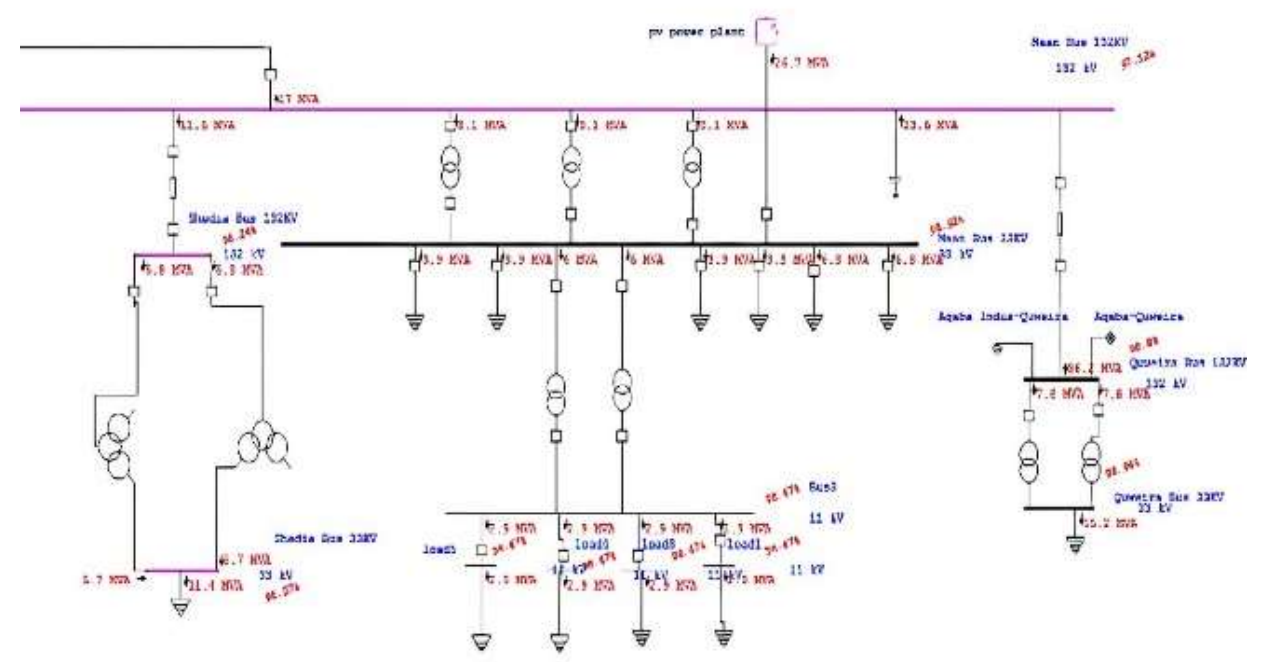

Figure 10. ETAP load flow diagram for case II

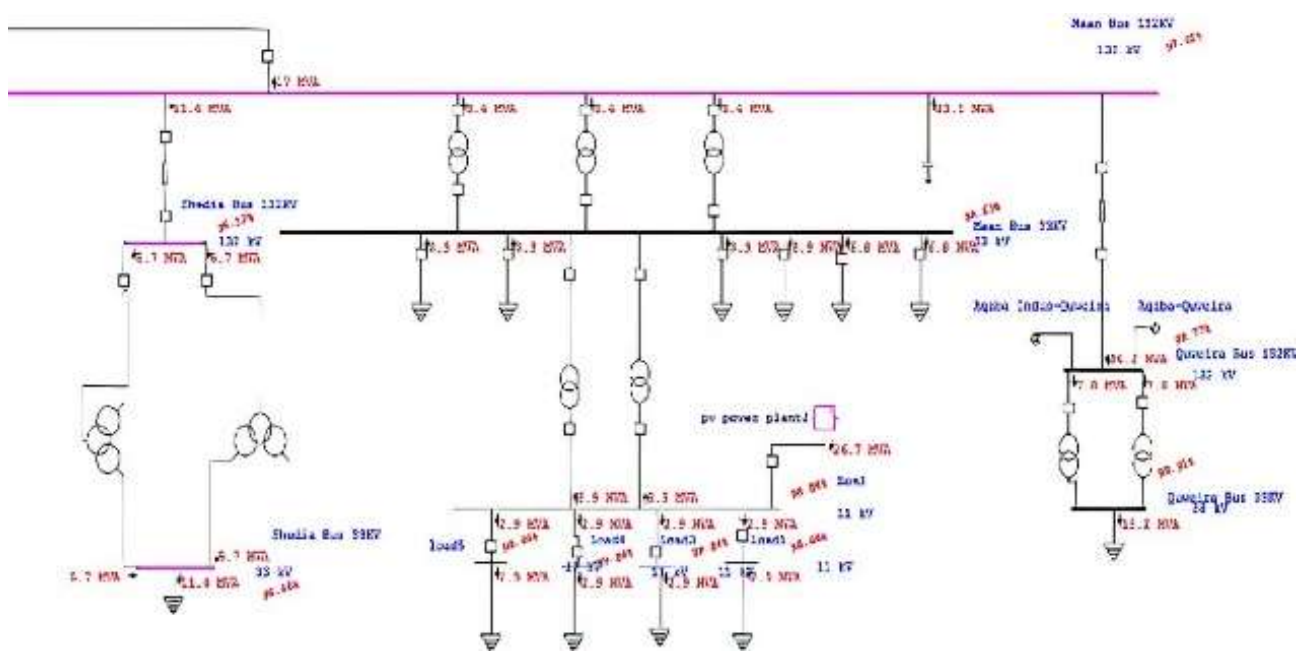

Figure 11. ETAP single line diagram for case III 


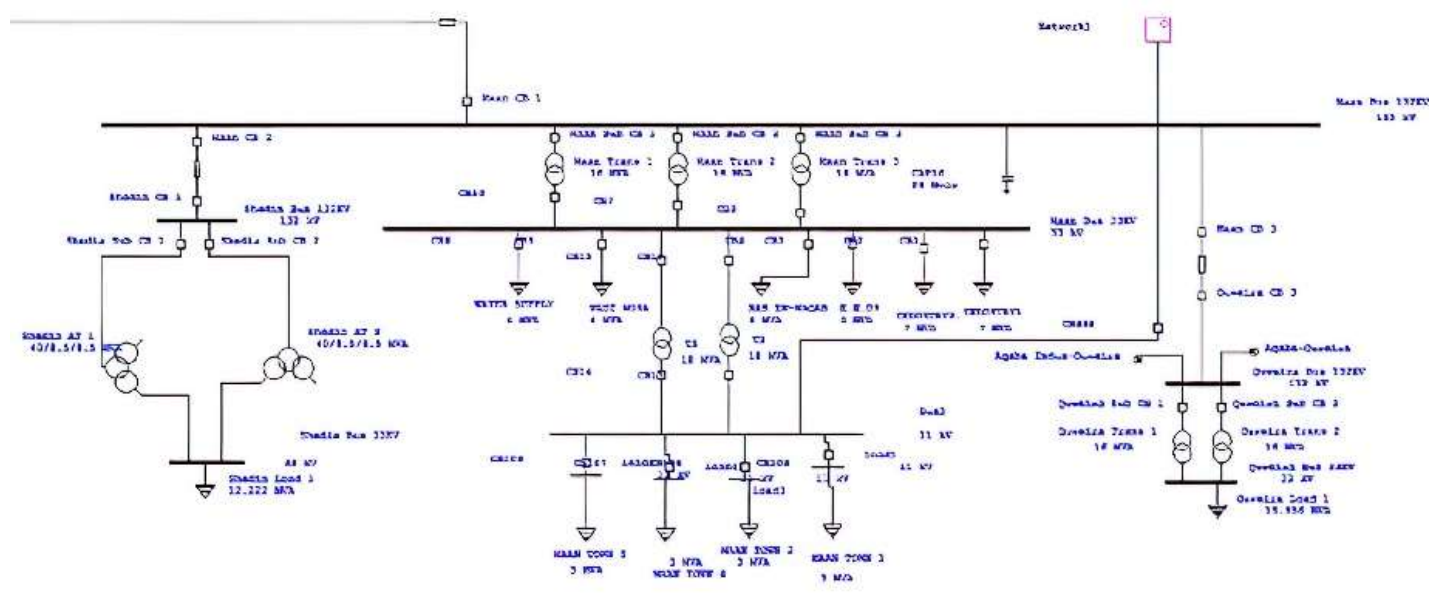

Figure 12. ETAP load flow diagram for case III

\section{IMPACT OF PV SYSTEM ON POWER LOSSES VALUES}

The overloads on highly loaded distribution feeders and release of capacity on these feeders and substation transformers are alleviated through large penetration of distributed PV solar generation. This favor deferring of capital investments to other areas by distribution planners. There is a minimization of total distribution power losses [34], [35].

According to the analysis of simulated results, the total power losses through the branches for the three cases are shown in Table 4. When connecting solar PV to the $33 \mathrm{kV}$ bus, the power losses moderatly decrease in comparison with the normal system power losses, while connecting the solar PV on $11 \mathrm{kV}$ bus, the losses decrease in comparison with the losses of the normal system. Figure 13 illustrates the power losses versus the penetration rate of the solar PV system.

Table 4. Power losses of the power network for different cases

\begin{tabular}{ccc}
\hline Penetration rate & Active power 33kV connection point [MW] & Active power losses 11kV connection point [MW] \\
\hline 0 & 55.68 & 55.68 \\
16 & 55.518 & 55.496 \\
33.3 & 55.37 & 55.34 \\
50 & 55.236 & 55.21 \\
66.6 & 55.115 & 55.106 \\
83 & 55.007 & 55.028 \\
100 & 54.912 & 54.978 \\
\hline
\end{tabular}

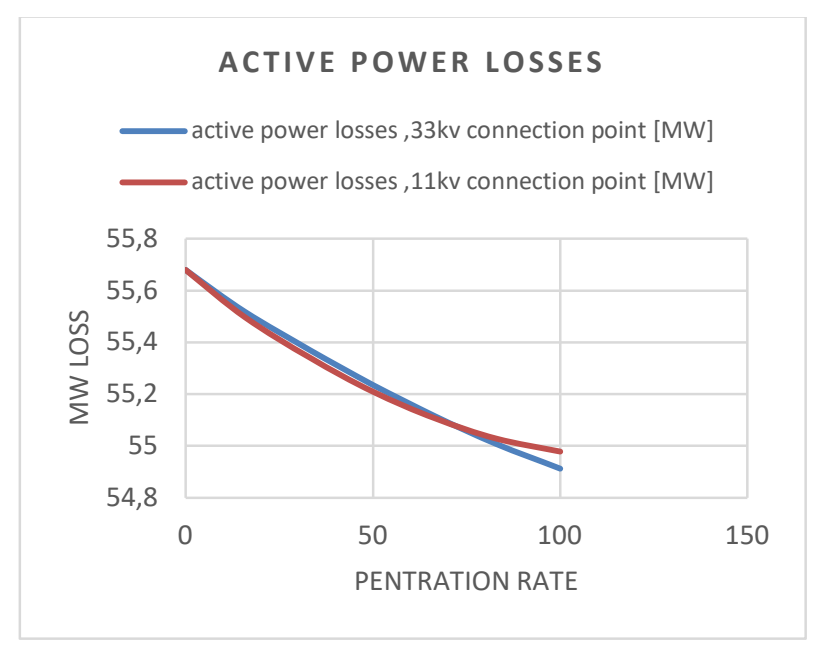

Figure 13. Active power losses versus penetration rate of PVs 


\subsection{Impact of PV system on voltage variation}

The high penetration of solar PV system poses a major concern to the distribution network in high steady state voltage generation. Depending on the network characteristics and the location of the PV system, the effect of the voltage varies [36]-[38]. In this paper, a load flow analysis of the distribution network has been performed for three cases. Table 5 shows bus voltages in percentage of the distribution network for the selected cases. Figure 14 illustrates the voltage profile versus the penetration rate of the solar PV system.

Table 5. Bus voltages in percentage of the distribution

\begin{tabular}{ccc} 
& \multicolumn{2}{c}{ network for different cases } \\
\hline $\begin{array}{c}\text { Penetration } \\
\text { rate }\end{array}$ & $\begin{array}{c}\text { Load bus Voltage } \% \\
\text { 33kV connection } \\
\text { point [MW] }\end{array}$ & $\begin{array}{c}\text { Load bus Voltage \% } \\
\text { 11kV connection point } \\
\text { [MW] }\end{array}$ \\
\hline 0 & 96.890 & 96.890 \\
16 & 97.209 & 97.491 \\
33.3 & 97.506 & 97.980 \\
50 & 97.78 & 97.360 \\
66.6 & 98.032 & 98.629 \\
83 & 98.261 & 98.791 \\
100 & 98.468 & 98.842 \\
\hline
\end{tabular}

\section{BUS VOLTAGES}

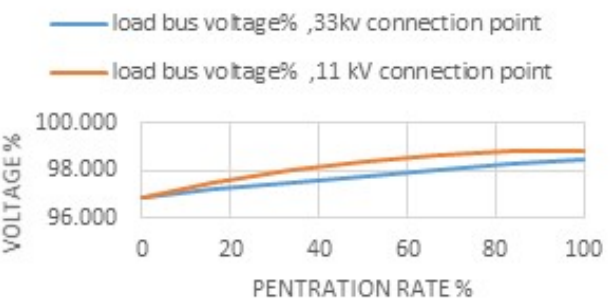

Figure 14. Voltage profile with various PV installation capacities

\subsection{Impact of the installed PV system on the short circuit current level}

Electrical systems with distributed generation of solar PV sources are exposed to some protection problems such as variations in the short circuit current levels, fault currents magnitudes and directions [39][40]. The peak and steady state values of three phase short circuit current are determined on the basis of short circuit calculations. The results are shown in Tables 6 and 7 in the studied cases. According to the finidngs, a significant increase in the nominal and peak value is observed, while a decrease in steady state at $33 \mathrm{kV}$ was found. While, at $11 \mathrm{kV}$ a significant increase in the peak values is observed in comparison with nominal $\mathrm{kV}$ and steady state KA. Figures 15 and 16 illustrate the short circuit current levels before and after connecting a $\mathrm{PV}$ system on $33 \mathrm{kV}$ and $11 \mathrm{kV}$ buses.

Table 6. the short circuit current levels before and after PV system connection ( $33 \mathrm{kV}$ shorted bus)

\begin{tabular}{lcccc}
\hline & Bus ID & Nominal kV & Peak Value[kA] & Steady State [kA] \\
\hline Original system & Ma'an Bus 33KV & 33 & 13.706 & 5.527 \\
Adding solar farm 33kv connection point & Ma'an Bus 33KV & 33 & 13.617 & 5.638 \\
Adding solar farm 11kv connection point & Ma'an Bus 33KV & 33 & 14.139 & 5.917 \\
\hline
\end{tabular}

Table 7. The short circuit current levels before and after PV system connection (11 kV shorted bus)

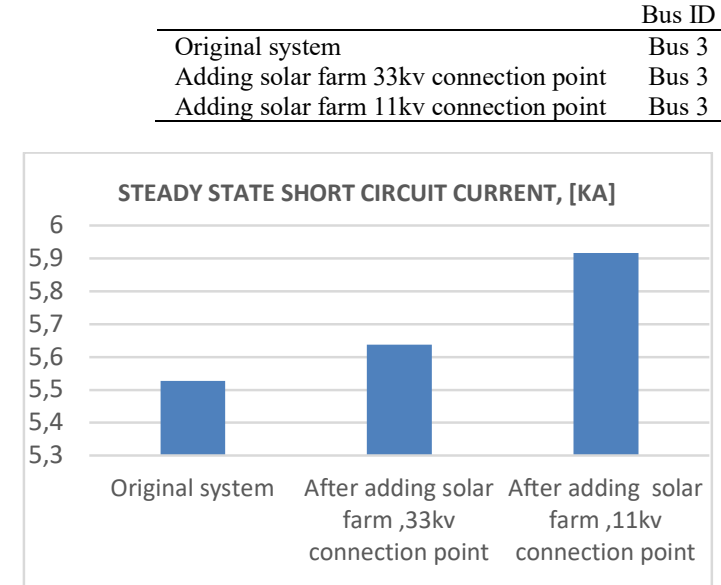

Figure 15. The short circuit current levels before

\begin{tabular}{ccc} 
Nominal kV & Peak Value[kA] & Steady State $[\mathrm{kA}]$ \\
11 & 19.003 & 7.56 \\
11 & 18.993 & 7.647 \\
11 & 19.502 & 8.435 \\
\hline
\end{tabular}

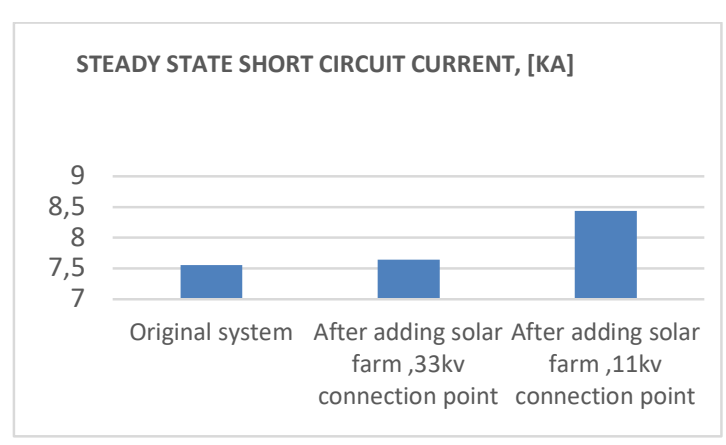

Figure 16. The short circuit current levels before and after PV system connection to 33 and $11 \mathrm{kV}$ and after PV system connection on $33 \mathrm{kV}$ buses (fault point at $33 \mathrm{kV}$ bus) (fault point at $11 \mathrm{kV}$ bus) 


\section{CONCLUSION}

This paper has discussed electricity production in Jordan by using or integrating renewable energy resources in the distributed generation systems. The system was designed and simulated using ETAP software. The study has also investigated the impact of connecting large scale solar PV energy plants with the national grid of Jordan by conducting load flow analysis. Moreover, there was evaluation of the effect of increasing the penetration levels of solar PVs, during normal conditions and power losses caused by faults. Integration of photovoltaic solar system marginally reduces the power losses. It provides a better distribution system voltage profile on the network elements, mainly when the photovoltaic solar system is connected to the power system near the center of loads. This improves the voltage stability of the system, especially under heavy inductive loads. The addition of PV system reduces the chance of voltage collapse. The short circuit current levels are slightly increased in the grid.and should be considered for protection settings.

\section{REFERENCES}

[1] A. Al-Mofleh and A. S. K. Dalabeeh, "Approach to Jordanian Energy Resource Efficiency Management Using Energy Efficiency Practices, " International Journal of Electrical and Electronic Science, vol. 4, no. 6, pp. 47-53, 2017.

[2] M. Al zou'bi, "Renewable Energy Potential and Characteristics in Jordan," Jordan Journal of Mechanical and Industrial Engineering, vol. 4, no. 1, pp. 45-48, Jan 2010.

[3] A. S. K. Dalabeeh, "Techno-economic analysis of wind power generation for selected locations in Jordan," Renewable Energy, vol. 101, pp. 1369-1378, Feb. 2010, doi: 10.1016/j.renene.2016.10.003.

[4] J. Jaber, O. O. Badran, and N. Abu-Shikhah, "Sustainable energy and environmental impact: role of renewables as clean and secure source of energy for the $21^{\text {st }}$ century in Jordan," Clean Technologies and Environmental Policy, vol. 6, no. 3, pp. 174-86, 2004, doi: 10.1007/s10098-003-0232-9.

[5] T. Key, "Finding a bright spot," in IEEE Power and Energy Magazine, vol. 7, no. 3, pp. 34-44, May-June 2009, doi: 10.1109/MPE.2009.932306.

[6] Y. Anagreh, A. Bataineh, and M. Al-Odat, "Solar energy potential in Jordan," in International Conference and Exhibition on Green Energy \& Sustainability for Arid Regions \& Mediterranean Countries ICEGES, Royal Hotel Amman, Jordan, 2009.

[7] Renewable Energy \& Energy Efficiency Law: Law No. (13) of 2012, https://www.memr.gov.jo/EN/List/Laws . [Accessed on $17^{\text {th }}$ of February 2020].

[8] A. S. K. Dalabeeh and A. Al-Mofleh, "Modeling of a High Performance Grid Connected Photovoltaic System," British Journal of Applied Science \& Technology, vol. 4, no. 32, pp. 4520-4532, Sep. 2014, doi: 10.9734/BJAST/2014/10983.

[9] Ministry Mineral and Energy of Resources, "Annual report," Amman, Jordan, 2015, http://www.memr.gov.jo/echobusv3.0/SystemAssets/6df2053d-ee21-4fa0-ada8-613049ab7015.pdf. [Accessed on $13^{\text {th }}$ of January of 2020$]$.

[10] K. Mentesidi and M. Aguado, "Dynamic behavior analysis of distributed generation in an off-grid network with power system simulator for engineering (PSS/E)," 2014 IEEE International Energy Conference (ENERGYCON), Cavtat, Croatia, 2014, pp. 1042-1049, doi: 10.1109/ENERGYCON.2014.6850553.

[11] A. S. K. Dalabeeh, "Wind Energy Using Doubly Fed Induction Generator," International Journal of Engineering and Innovative Technology (IJEIT), vol. 3, no. 1, pp. 446-450, July 2013.

[12] K. Mentesidi and M. Aguado, "The potential integration of electrical distributed generation in an island power system," International journal of distributed energy resources and smart grids, vol. 9, no. 4, pp. 341-366, 2013.

[13] Á. Ruiz, "System aspects of large-scale implementation of a photovoltaic power plant," Master Thesis, Kungliga Tekniska Högskolan, Stockholm, Sweden, 2011.

[14] B. Tamimi, C. Cañizares and K. Bhattacharya, "Modeling and performance analysis of large solar photo-voltaic generation on voltage stability and inter-area oscillations," 2011 IEEE Power and Energy Society General Meeting, Detroit, MI, USA, 2011, pp. 1-6, doi: 10.1109/PES.2011.6039797.

[15] H. S. Kamil, D. M. Said, M. W. Mustafa, M. R. Miveh, and N. Ahmad, "Low-voltage Ride-through Methods for Grid-connected Photovoltaic Systems in Microgrids: A Review and Future Prospect," International Journal of Power Electronics and Drive System (IJPEDS), vol. 9, no. 4, pp. 1834-1841, December 2018, doi: 10.11591/ijpeds.v9.i4.pp1834-1841.

[16] N. I. Zolkifri., C. K. Gan, and M. Shamsiri, "Performance analysis of Malaysian low voltage distribution network under different solar variability days," Indonesian Journal of electrical Engineering and Computer Science, vol. 13, no. 3, pp. 1152-1160, March 2019, doi: 10.11591/ijeecs.v13.i3.pp1152-1160.

[17] M. A. Awadallah, B. Venkatesh and B. N. Singh, "Impact of Solar Panels on Power Quality of Distribution Networks and Transformers," in Canadian Journal of Electrical and Computer Engineering, vol. 38, no. 1, pp. 4551, winter 2015, doi: 10.1109/CJECE.2014.2359111.

[18] I. Lillo-Bravo, P. González-Martínez, M. Larrañeta, and J. Guasumba-Codena, "Impact of energy losses due to failures on photovoltaic plant energy balance," Energies, vol. 11, no. 2, pp. 363, 2018, doi: 10.3390/en11020363.

[19] E. Mulenga, "Impacts of integrating solar PV power to an existing grid. Case Studies of Mölndal and Orust energy distribution (10/0.4 kV and 130/10 kV) grids," Master Thesis, Chalmers University of Technology, Gothenburg, Sweden 2015.

Bulletin of Electr Eng \& Inf, Vol. 10, No. 3, June 2021 : 1129-1141 
[20] S. Azzam, E. Feilat and A. Al-Salaymeh, "Impact of connecting renewable energy plants on the capacity and voltage stability of the national grid of Jordan," 2017 8th International Renewable Energy Congress (IREC), Amman, Jordan, 2017, pp. 1-6, doi: 10.1109/IREC.2017.7926004.

[21] I. Etier, M. Ababneh, and A. Al Tarabsheh, "Simulation of a $10 \mathrm{~kW}$ Photovoltaic System in Areas with High Solar Irradiation, "American Journal of Applied Sciences", vol. 8, no. 2, pp. 177-181, 2011.

[22] International Renewable Energy Agency(IRENA): Renewable Energy Cost Analysis: Concentrating Solar Power. https://irena.org/publications/2012/Jun/Renewable-Energy-Cost-Analysis---Concentrating-Solar-Power

[23] N. I. A. Tawalbeh, "Daily load profile and monthly power peaks evaluation of the urban substation of the capital of Jordan Amman," International Journal of Electrical Power \& Energy Systems, vol. 37, no. 1, pp. 95-102, 2012, doi: 10.1016/j.ijepes.2011.12.010.

[24] O. Al-Nhoud and M. Al-Smairan, "Assessment of Wind Energy Potential as a Power Generation Source in the Azraq South, Northeast Badia, Jordan," Modern Mechanical Engineering, vol. 5, no. 3, pp. 87-96, 2015, doi: $10.4236 / \mathrm{mme} .2015 .53008$.

[25] M. Saeedan, "Sustainable Energy Mix and Policy Framework for Jordan," Friedrich Ebert Stiftung: Amman, Jordan, 2011, http://library.fes.de/pdffiles/bueros/amman/08883.pdf. Accessed on 26 $6^{\text {th }}$ of December 2019.

[26] R.A. Abdallah, S. Ali, Dalabeeh and A. Almofleh, "Power Losses Minimization Using on Load Tap Changer Transformers and Injected Reactive Power," Journal of Engineering and Applied Sciences, vol. 13, no. 8, pp. 21562161, 2018, doi: 10.3923/jeasci.2018.2156.2161.

[27] E. Cammaňon-Martín, et al., "Interaction between photovoltaic distributed generation and electricity networks," Progress in Photovoltaics: research and applications, vol. 16, pp. 629-643, 2008, doi: 10.1002/pip.845.

[28] S. KoohiKamali, S. Yusof, J. Selvaraj and M. N. B. Esa, "Impacts of grid-connected PV system on the steady-state operation of a Malaysian grid," 2010 IEEE International Conference on Power and Energy, Kuala Lumpur, Malaysia, 2010, pp. 858-863, doi: 10.1109/PECON.2010.5697699.

[29] S. Sharma and B. R. Parekh, "Impact of PVPS (Photovoltaic Power System) Connection to Grid in Urban Areas," In National Conference on Recent Trends in Engineering \& Technology, Gujarat, India, 2011, pp. 1-5.

[30] H. Saadat, "Power System Analysis," New York-USA, PSA Publishing, 2010.

[31] S. Kulkarni and S. Sontakk, "Power System Analysis of a Micro grid using ETAP," International Journal of Innovative Science and Modern Engineering (IJISME), vol. 3, no. 5, pp. 2319-6386, April 2015, doi: 10.13140/RG.2.2.24287.87206.

[32] A. S. Dalabeeh, A. Almofleh, A. R. Alzyoud, and H. T. Ayman, "Economical and Reliable Expansion Alternative of Composite Power System under Restructuring," International Journal of Electrical and Computer Engineering (IJECE), vol. 8, no. 6, pp. 4790-4799, 2018, doi: 10.11591/ijece.v8i6.pp4790-4799.

[33] A.E. Curtright and J. Apt, "The Character of Power Output from Utility-Scale Photovoltaic Systems," Progress in Photovoltaics: Research and Applications, vol. 16, no. 3, pp. 241-247, 2008, doi: 10.1002/pip.786.

[34] Quanta Technology White Paper: "Grid Impacts and Solutions of Renewables at High Penetration Levels," June 2009, hhttp://www.quantatechnology.com. [Accessed on $15^{\text {th }}$ of January 2020].

[35] A. F. Povlsen, "Distributed power using PV: Challenges for the grid, "Renewable ENERGY World, vol. 6, pp. 6273, 2003.

[36] R. Tonkoski, D. Turcotte and T. H. M. EL-Fouly, "Impact of High PV Penetration on Voltage Profiles in Residential Neighborhoods," in IEEE Transactions on Sustainable Energy, vol. 3, no. 3, pp. 518-527, July 2012, doi: 10.1109/TSTE.2012.2191425.

[37] A. M. J. Jeman, N. Hannoon, N. Hidayat, M. M. H. Adam, I. Musirin, and V. Vijayakumar,"Simulation on microgrid connected PV system under balance and unbalance fault," Indonesian Journal of Electrical Engineering and Computer Science, vol. 13, no. 3, pp. 1332-1336, March 2019, doi: 10.11591/ijeecs.v13.i3.pp1332-1336.

[38] D. Cheng, B. A. Mather, R. Seguin, J. Hambrick and R. P. Broadwater, "Photovoltaic (PV) Impact Assessment for Very High Penetration Levels," in IEEE Journal of Photovoltaics, vol. 6, no. 1, pp. 295-300, Jan. 2016, doi: 10.1109/JPHOTOV.2015.2481605.

[39] M. Al-Halalmeh and S. Al-Jufout, "Impact of Photovoltaic Penetration on the Distribution System Protection: A Case Study of 5-MW Plants of Mu'tah University and Kempinski Hotel," 2019 IEEE Jordan International Joint Conference on Electrical Engineering and Information Technology (JEEIT), Amman, Jordan, 2019, pp. 228-233, doi: 10.1109/JEEIT.2019.8717390.

[40] H. Hooshyar and M. E. Baran, "Fault Analysis on Distribution Feeders With High Penetration of PV Systems," in IEEE Transactions on Power Systems, vol. 28, no. 3, pp. 2890-2896, Aug. 2013, doi: 10.1109/TPWRS.2012.2227842. 